• 研究报告・

\title{
东乡野生稻可培养内生细菌群落组成及多样性
}

\author{
陈志远 ${ }^{1}$ 刘 珺 ${ }^{1}$ 杨星鹏 ${ }^{1}$ 刘 梦 ${ }^{1}$ 汪 涯 ${ }^{2}$ 张志斌 $^{*}$ 朱
1(江西师范大学生命科学学院, 江西省亚热带植物资源保护与利用重点实验室, 南昌 330022)
2 (江西科技师范大学生命科学学院, 江西省生物加工过程重占实验至, 南昌 330013)
}

摘要: 内生细菌对宿主植物生长发育和生理代谢具有重要影响, 揭示其群落组成和多样性具有重要的生物学和生 态学意义。本研究采用可培养法从东乡野生稻(Oryza rufipogon)不同组织中分离获得94株内生细菌, 基于16S rRNA 基因序列比对和系统发育分析将其归属于变形菌门、放线菌门和厚壁菌门3门14科17属, 其中芽孢杆菌属(Bacillus) 和微小菌属(Microbacterium) 为优势属, 分别占总株数的 $27.7 \%$ 和 $20.2 \%$ 。不同组织中内生细菌的分布和多样性存在 差异, 根中内生细菌数量最多 (34株, 36.2\%), 叶次之 (32株, 34.0\%), 茎最少 (28株, 29.8\%); 根中内生细菌 Shannon-Wiener多样性指数 $\left(H^{\prime}=2.52\right)$ 、Simpson优势度指数 $(D=0.88)$ 和Pielou均匀度指数 $(E=0.72)$ 均高于茎与叶, 根和茎的Jaccard相似性系数 $(C=0.29)$ 低于根和叶 $(C=0.47)$ 以及茎和叶 $(C=0.45)$ 。研究结果表明, 东乡野生稻内生 细菌具有丰富的物种多样性, 并且不同组织部位的内生细菌组成存在差异, 根中内生细菌多样性最丰富。

关键词：野生稻; 植物内生菌; 分类; 系统发育; 组成分析

\section{Community composition and diversity of cultivable endophytic bacteria isolated from Dongxiang wild rice}

\begin{abstract}
Zhiyuan Chen ${ }^{1}$, Jun Liu $^{1}$, Xingpeng Yang ${ }^{1}$, Meng Liu ${ }^{1}$, Ya Wang ${ }^{2}$, Zhibin Zhang ${ }^{1 *}$, Du Zhu ${ }^{1,2^{*}}$
1 Key Laboratory of Protection and Utilization of Subtropical Plant Resources of Jiangxi Province, College of Life Sciences, Jiangxi Normal University, Nanchang 330022

2 Key Laboratory of Bioprocess Engineering of Jiangxi Province, College of Life Sciences, Jiangxi Science and Technology Normal University, Nanchang 330013
\end{abstract}

\begin{abstract}
Endophytic bacteria are essential to the growth and metabolism of their host plants. To better understand the community structure and diversity of endophytic bacteria on plants, we isolated 94 strains of endophytic bacteria from the roots, stems and leaves of Dongxiang wild rice (Oryza rufipogon). Subsequent 16S rRNA sequence alignments and phylogenetic analyses revealed that the 94 strains could be categorized into 17 genera of 14 families in 3 phyla (Proteobacteria, Actinobacteria, and Firmicutes).Bacillus and Microbacterium, accounting for $27.7 \%$ and $20.2 \%$ of the diversity, respectively, were the two most dominant genera. The distribution and diversity of endophytic bacteria differed across different tissues of Dongxiang wild rice: the roots contained the most endophytic bacteria strains $(n=34,36.2 \%)$, followed by leaves $(n=$ 32, 34.0\%), and stems $(n=28,29.8 \%)$. Shannon-Wiener diversity index $\left(H^{\prime}=2.52\right)$, Simpson dominance index $(D=0.88)$ and Pielou evenness index $(E=0.72)$ were higher in the roots than in the stems or leaves. Meanwhile, the Jaccard similarity index between roots and stems $(C=0.29)$ was lower than that between roots and leaves $(C=0.47)$, or that between stems and leaves $(C=0.45)$. Our efforts to uncover the diversity of endophytic bacteria in Dongxiang wild rice confirms that roots contain the most diverse strains but that the composition of endophytes varies across tissues.
\end{abstract}

Key words: Oryza rufipogon; endophytes; classification; phylogeny; composition analysis

植物内生细菌是指可定殖在健康植物细胞间 隙或细胞内的一类细菌(James \& Olivares, 1998),
多样性十分丰富。植物内生细菌分布于植物不同组 织部位(Baldan et al, 2014), 而且随着气候条件以及

收稿日期: 2019-07-07; 接受日期: 2019-10-20

基金项目: 国家自然科学基金(31760160)、江西省自然科学基金(20171BAB204009; 20181BAB215044)和江西师范大学研究生创新项目(YJS2018080; YC2019-S121)

* 通讯作者 Author for correspondence. E-mail: zzbbio@jxnu.edu.cn 
植物生长期的不同, 其种类和组成呈现出显著的差 异(Reinhold-Hurek \& Hurek, 2011)。在与宿主长期协 同进化过程中, 植物内生细菌与宿主间通过建立互 惠共生关系, 不仅能有效提升宿主植物的抗病虫害 能力(Pavlova et al, 2017)和抗逆能力(Faria et al, 2013), 促进其生长发育(Tsavkelova et al, 2016), 而 且对于维持宿主植物微生态系统的动态平衡具有 重要作用(Brundrett \& Tedersoo, 2018)。植物内生细 菌多样性的研究对于揭示内生细菌与宿主植物的 互作机制, 评价宿主植物生长状况与内环境的稳定 性(Shao et al, 2017), 开发生防种质资源等都具有重 要意义(Tsavkelova et al, 2007)。

普通野生稻(Oryza rufipogon)作为栽培稻的祖 先(宋志平等, 2018), 具有高产、抗病害、耐逆境等 优良品性, 现有研究表明, 这些优良品性与其内生 细菌紧密相关(胡桂萍等, 2010)。迄今, 研究人员已 从栽培稻中分离到高固氮酶活性(谭志远等, 2009)、 产IAA和铁载体物质(Loaces et al, 2011)等活性的内 生细菌, 它们不仅能增强栽培稻抗逆境能力(Shahzad et al, 2017)和抗病虫害能力(Liu et al, 2017), 而 且能促进植物合成多种植物生长激素(Shylla et al, 2016; Shahzad et al, 2017), 并有效提高植物氮吸收 与氮代谢水平(杨波等, 2013; Rangjaroen et al, 2014), 在植物的生长过程中扮演重要角色。东乡野生稻是 我国发现分布最北的野生稻(陈家宽等, 1998), 显示 出高产、抗逆等众多优良性状, 因而被广泛用于种 质资源与抗性基因的挖掘(Li et al, 2010; Zhang et al, 2016)。虽然已有东乡野生稻根际微生物群落特征和 促生抗病活性菌株笁选的报道(罗菲等, 2011; Dai et al, 2011), 但有关其内生细菌多样性和生态分布规 律的相关研究未见报道。本文选择中国特有资源东 乡野生稻为研究材料, 研究植株内生细菌的多样性 及其在不同组织部位的定殖特点, 探索其生态分布 规律, 为进一步揭示植物内生细菌群落的生态学意 义以及挖掘功能菌株提供参考。

\section{材料与方法}

\section{1 样品采集与预处理}

东乡野生稻植株材料于2014年10月采自江西 省抚州市东乡县岗上积镇东乡野生稻原位保护区 内 $\left(28^{\circ} 14^{\prime} \mathrm{N}, 116^{\circ} 30^{\prime} \mathrm{E}\right)$ 。野外采样时, 随机选取相 隔一定距离且长势较好的野生稻植株5株, 采集样
品放入无菌采样袋中，低温保存运回实验室，并在 $24 \mathrm{~h}$ 内进行内生菌分离。

\section{2 培养基}

分离培养基。(1)牛肉膏蛋白胨培养基(NA): 蛋 白胨 $10.0 \mathrm{~g}$, 牛肉膏 $3.0 \mathrm{~g}, \mathrm{NaCl} 5.0 \mathrm{~g}$, 琼脂 $15.0 \mathrm{~g}$, 蒸馏水1,000 mL, pH 7.2-7.4。(2) 10倍稀释的牛肉膏 蛋白胨培养基 $(\mathrm{NA} \times 10): \mathrm{NA}$ 营养成分稀释 10 倍，琼 脂15.0 g, pH 7.2-7.4。(3) Baird-Parker agar (BPA): 酪蛋白水解液 $10.0 \mathrm{~g}$, 甘氨酸 $10.0 \mathrm{~g}, \mathrm{NaCl} 5.0 \mathrm{~g}$, 牛 肉亳 $5.0 \mathrm{~g}$, 酵母提取物 $1.0 \mathrm{~g}$, 琼脂 $15.0 \mathrm{~g}$, 蒸馏水 1,000 mL, pH 7.2。(4)任氏培养基(R2A)。(5)胰酶大 豆琼脂培养基(TSA)均购自广州环凯微生物科技有 限公司。

传代培养及形态观察培养基为牛肉膏蛋白胨 培养基(NA)。

\section{3 内生细菌的分离、纯化和保藏}

植株样品预处理：将采集的野生稻样品用自来 水冲洗外表面并除去坏死组织, 然后超声清洗去除 与根部紧密结合的土壤。将清洗干净的水稻样品放 置于阴凉通风处晾干。接下来将晾干后的植株进行 表面消毒处理: 在无菌条件下将植株的根、茎、叶 剪断分开，并将每种组织分别切成3-5 $\mathrm{cm}$ 的小块, 用 $5 \%$ 的次氯酸钠处理 $5 \mathrm{~min}$, 无菌水清洗，再用 $75 \%$ 乙醇处理3 min, 最后用无菌水清洗3-5次除去 残留乙醇; 同时取最后一次清洗样品的无菌水200 $\mu \mathrm{L}$ 涂布于 5 种不同的培养基上，以验证表面消毒是 否彻底, 确保分离所得菌株为内生细菌。将消毒后 的植物样品置于无菌的铺有滤纸的培养血中, 在无 菌操作台中通风干燥备用。

植株组织内生细菌的分离纯化: 取表面消毒干 燥后的根茎叶, 分别置于无菌操作台中研磨粉碎, 加入 $20 \mathrm{~mL}$ 无菌蒸馏水制成研磨液后, 将所得研磨 液逐步稀释到 $10^{-1}-10^{-5}$ 浓度梯度，取各梯度浓度稀 释液 $200 \mu \mathrm{L}$ 分别涂布到含制霉菌素 $(50 \mu \mathrm{g} / \mathrm{mL})$ 的分 离琼脂培养基中 $(N A 、 N A \times 10 、 T S A 、 B P A 、 R 2 A)$ 进行内生细菌分离。

菌种样品保藏: 将上述培养基置于 $37^{\circ} \mathrm{C}$ 恒温培 养箱中培养1-3 d, 根据菌落形态、颜色特征挑取单 细菌菌落, 经反复划线纯化得到纯培养物, 并将分 离纯化所得菌株冷冻保存 $\left(-80^{\circ} \mathrm{C}\right)$ 在含 $30 \%$ 的甘油 管中。 
1.4 内生细菌DNA提取、16S rRNA基因序列扩增 测序和序列比对分析

根据菌落形态特征挑取不同菌落在培养基平 板上纯化, 结合镜检确定其为单一形态; 选择代表 性菌株, 参考《常见细菌系统鉴定手册》(东秀珠和 蔡妙英, 2001)中的相关方法进行初步鉴定。将细菌 在 $37^{\circ} \mathrm{C}$ 恒温培养 $24 \mathrm{~h}$ 后, 收获菌体, 用DNA试剂盒 (OMEGA公司)提取各菌株基因组DNA，采用通用 引物 27F (5'-AGAGTTTGATCCTGGCTCAG-3') 和 1492R (5'-GGTTACCTTGTTACGACTT-3') 扩增16S rRNA基因序列。PCR扩增反应体系 $(50 \mu \mathrm{L}): \mathrm{ddH}_{2} \mathrm{O}$ $22 \mu \mathrm{L}$; 引物 $(10 \mu \mathrm{M})$ 各 $1 \mu \mathrm{L}$; 模板DNA $1 \mu \mathrm{L}$; Mix Taq酶: $25 \mu \mathrm{L}$ 。PCR反应条件: $94^{\circ} \mathrm{C}$ 预变性 $5 \mathrm{~min}$, $94^{\circ} \mathrm{C}$ 变性 $40 \mathrm{~s}, 55^{\circ} \mathrm{C}$ 复性 $40 \mathrm{~s}, 72^{\circ} \mathrm{C}$ 延伸 $1 \mathrm{~min}, 30$ 个 循环。反应完成后, $72^{\circ} \mathrm{C}$ 延伸 $10 \mathrm{~min}, 4^{\circ} \mathrm{C}$ 保存。PCR 产物纯化后送上海英杰生物科技有限公司测序。

将所获得的16S rRNA基因序列提交到NCBI网 站, 与核苷酸数据库中有效描述的 $16 \mathrm{~S}$ rRNA基因 序列相比对, 使用MEGA X软件以neighbour-joining 法构建分子系统发育树。初步判定菌株所属类群, 确定东乡野生稻内生细菌的种属地位。

\section{5 内生细菌多样性分析}

根据方法1.4节中菌株BLAST比对结果, 基于 东乡野生稻不同组织部位分离菌株所属类群及细 菌分离来源, 用以下公式对其分布的多样性与相似 性进行计算:

Shannon-Wiener多样性指数 $\left(H^{\prime}\right)$ (Shannon, 1948):

$$
H^{\prime}=-\sum_{i=1}^{N} P_{i} \ln P_{i}
$$

式中: $P_{\mathrm{i}}=N_{\mathrm{i}} / N$, 其中 $N_{\mathrm{i}}$ 为来源于植物不同组织第 $\mathrm{i}$ 属的个体数, $N$ 为全部属的菌株个体数之和。

Simpson优势度指数 $(D)$ (Greenberg, 1956):

$$
D=1-\sum P_{i}^{2}
$$

式中: $P_{\mathrm{i}}$ 属的个体数占群落中总属数的比例。

Pielou均匀度指数 $(E)$ (Pielou, 1966):

$E=H^{\prime} / H_{\max }$

式中: $H^{\prime}$ 为实际的物种多样性指数, $H_{\max }$ 为最大的物 种多样性指数, $H_{\max }=\ln S$ (S为群落中的总物种数)。

Jaccard相似性指数 $(C)$ (Whittaker, 1972):

$$
C=j /(a+b-j)
$$

式中: $j$ 表示两种不同组织中共同具有的内生细菌属
数, $a$ 表示其中一种组织中内生细菌的属数, $b$ 表示 另一种组织中内生细菌的属数。

\section{结果}

\section{1 东乡野生稻内生细菌组成}

从东乡野生稻根、茎和叶3种不同组织部位中 共分离获得94株内生细菌(表1)。其中根部内生细菌 最多, 为34株; 其次为叶, 32株; 最少为茎, 28株(表 1)。比较 5种培养基的分离效果发现(图1A), NA × 10 培养基和NA培养基分离菌株数多于其他 3 种培养 基，占比分别为26.5\%和24.4\% (图1B)。

根据BLAST比对结果(表1), 将94株东乡野生 稻内生细菌初步归属为37个种。基于16S rRNA基因 序列构建的代表菌株与GenBank数据库中近缘菌株 的系统发育树(图2)分析结果表明，分离的内生菌株 分属于变形菌门、放线菌门和厚壁菌门3门17属, 且 代表菌株与GenBank数据库中近缘菌株16S rRNA 基因序列的相似度为 $97 \%-100 \%$ 。

属于变形菌门的内生细菌有28株，占分离总株 数的 $29.8 \%$, 包括肠杆菌科、鞘氨醇单胞菌科、根瘤 菌科、甲基杆菌科、假单胞菌科、黄色单胞菌科和 莫拉氏菌科 7 科 8 属; 根瘤菌科包括土壤杆菌属 (Agrobacterium)和根瘤菌属(Rhizobium) 2属, 肠杆 菌科、鞘氨醇单胞菌科、甲基杆菌科、假单胞菌科、 黄色单胞菌科和莫拉氏菌科下各 1 属, 分别为泛菌 属(Pantoea)、鞘氨醇单胞菌属(Sphingomonas)、甲 烷细菌属(Methylobacterium)、假单胞菌属(Pseudomonas)、寡养单胞菌属(Stenotrophomonas)和不动杆 菌属(Acinetobacter)。泛菌属为变形菌门中的优势属, 共分离到12株，占分离总菌株数的 $12.8 \%$ 。

属于放线菌门的内生细菌有32株，占分离总株 数的 $34.0 \%$, 包括微杆菌科、雷弗森菌科、诺卡氏菌 科、微球菌科和分支杆菌科5科6属; 微杆菌科包括 微小菌属(Microbacterium)和短杆菌属(Curtobacterium) 2 属, 雷弗森菌科、诺卡氏菌科、微球菌科和分 支杆菌科下各1属, 分别为雷弗森菌属(Leifsonia)、 红球菌属(Rhodococcus)、节杆菌属(Arthrobacter)和 分支杆菌属(Mycobacterium)。微小菌属为放线菌门 中的优势属, 共分离到19株, 占分离总菌株数的 $20.2 \%$ 。

属于厚壁菌门的内生细菌有34株，占分离总株 数的 $36.2 \%$, 包括芽狍杆菌科和类芽狍杆菌科 2 科3 
表1 东乡野生稻不同组织中内生细菌的分布情况

Table 1 The distribution of endophytic bacteria isolated from different tissues of Dongxiang wild rice

\begin{tabular}{|c|c|c|c|c|c|c|}
\hline \multirow[t]{2}{*}{$\begin{array}{l}\text { 代表菌株 } \\
\text { Representative strains }\end{array}$} & \multirow{2}{*}{$\begin{array}{l}\text { NCBI库中相似度最高菌种 } \\
\text { (登录号) } \\
\text { Closest relatives in NCBI } \\
\text { (GenBank accession no.) }\end{array}$} & \multirow{2}{*}{$\begin{array}{l}\text { 基因登录号 } \\
\text { GenBank } \\
\text { accession } \\
\text { no. }\end{array}$} & \multirow{2}{*}{$\begin{array}{l}\text { 序列相 } \\
\text { 似度 } \\
\text { Identity } \\
(\%)\end{array}$} & \multicolumn{2}{|c|}{$\begin{array}{l}\text { 分离菌株数 } \\
\text { No. of strains }\end{array}$} & \multirow{2}{*}{$\begin{array}{l}\text { 培养基分离菌株数 } \\
\text { No. of strains from medium } \\
\text { NA BPA R2A TSA NA×1 }\end{array}$} \\
\hline & & & & $\begin{array}{l}\text { 根 } \\
\text { Root }\end{array}$ & $\begin{array}{ll}\text { 茎 } & \text { 叶 } \\
\text { Stem } & \text { Leaf }\end{array}$ & \\
\hline
\end{tabular}

\section{变形菌门 Proteobacteria}

\section{泛菌属 Pantoea}

$\begin{array}{ll}\text { JXR10 } & \text { Pantoea sp. (JX994157.1) } \\ \text { JXS8 } & \text { Pantoea sp. (KJ733870.1) } \\ \text { JXL1 } & \text { Pantoea sp. (KJ733870.1) }\end{array}$

鞘氨醇单胞菌属 Sphingomonas

$\begin{array}{cc}\text { JXR34 } & \text { Sphingomonas yanoikuyae (KJ009 } \\ \text { JXL6 } & \text { Sphingomonas sanguinis (NR113637. } \\ \text { 土壤杆菌属 } & \text { Agrobacterium } \\ \text { JXS10 } & \text { Agrobacterium sp. (GQ169803.1) } \\ \text { JXL9 } & \text { Agrobacterium sp. (KJ184856.1) }\end{array}$

甲烷细菌属 Methylobacterium

$\begin{array}{ll}\text { JXR16 } & \text { Methylobacterium sp. (KM083547.1) } \\ \text { JXS9 } & \text { Methylobacterium sp. (AB604650.1) } \\ \text { JXL16 } & \text { Methylobacterium sp. (KM083546.1) }\end{array}$

假单胞菌属 Pseudomonas

$\begin{array}{ll}\text { JXR26 } & \text { Pseudomonas sp. (HE978359.1) } \\ \text { JXL21 } & \text { Pseudomonas fulva (AY741159.1) }\end{array}$

寡养单胞菌属Stenotrophomonas

JXS14

Stenotrophomonas maltophilia (JN571747.1)

根瘤菌属 Rhizobium

JXS18

Rhizobium sp. (JN082742.1)

不动杆菌属 Acinetobacter

JXR29

Acinetobacter oleivorans (KJ806471.1)

\section{放线菌门 Actinobacteria}

微小菌属 Microbacterium

JXR14
JXS2
JXL7
JXL12

短杆菌属 Curtobacterium

$\begin{array}{ll}\text { JXR24 } & \text { Curtobacterium citreum (KC329830.1) } \\ \text { JXS1 } & \text { Curtobacterium luteum (JQ660182.1) } \\ \text { JXL30 } & \text { Curtobacterium sp. (KC841444.1) }\end{array}$

分支杆菌属 Mycobacterium

JXR17

Mycobacterium sp. (AB605021.1)

节杆菌属 Arthrobacter

JXR12

Microbacterium trichothecenolyticum (KF953537.1)

Microbacterium sp. (AB773218.1)

Microbacterium sp. (EU741023.1)

Microbacterium laevaniformans

(KC252695.1)

Arthrobacter phenanthrenivorans (KC934897.1)

$\begin{array}{ll}\text { KP980595 } & 100 \\ \text { KP980579 } & 100 \\ \text { KP980566 } & 100\end{array}$

KP980605 100

KP980568 100

KP980581 100

KP980570 100

KP980599 100

KP980580 100

KP980572 100

KP980602 100

KP980573 100

KP980583 100

KP980584 100

KP980603 100

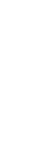

$\begin{array}{llllllll}5 & 1 & 6 & 3 & 2 & 3 & 2 & 2\end{array}$

00

(n)

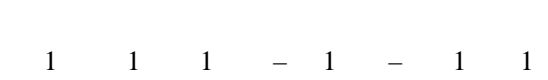




\begin{tabular}{|c|c|c|c|c|c|c|c|c|c|c|c|}
\hline \multirow[t]{2}{*}{$\begin{array}{l}\text { 代表菌株 } \\
\text { Representative strains }\end{array}$} & \multirow{2}{*}{$\begin{array}{l}\text { NCBI库中相似度最高菌种 } \\
\text { (登录号) } \\
\text { Closest relatives in NCBI } \\
\text { (GenBank accession no.) }\end{array}$} & \multirow{2}{*}{$\begin{array}{l}\text { 基因登录号 } \\
\text { GenBank } \\
\text { accession } \\
\text { no. }\end{array}$} & \multirow{2}{*}{$\begin{array}{l}\text { 序列相 } \\
\text { 似度 } \\
\text { Identity } \\
(\%)\end{array}$} & \multicolumn{3}{|c|}{$\begin{array}{l}\text { 分离株数 } \\
\text { No. of strains }\end{array}$} & \multicolumn{5}{|c|}{$\begin{array}{l}\text { 培养基分离株数 } \\
\text { No. of strains from medium }\end{array}$} \\
\hline & & & & $\begin{array}{l}\text { 根 } \\
\text { Root }\end{array}$ & $\begin{array}{l}\text { 茎 } \\
\text { Stem }\end{array}$ & $\begin{array}{l}\text { 叶 } \\
\text { Leaf }\end{array}$ & & $\mathrm{ABPA}$ & R2A & TSA & $\mathrm{NA} \times 10$ \\
\hline 雷弗森菌属 Leifsonia & & & & 3 & - & - & - & - & 1 & - & 2 \\
\hline JXR6 & Leifsonia sp. (KJ944083.1) & КР980592 & 100 & & & & & & & & \\
\hline 红球菌属 Rhodococcus & & & & 1 & - & - & - & - & - & 1 & - \\
\hline JXR8 & Rhodococcus equi (NR041910.1) & КР980594 & 100 & & & & & & & & \\
\hline \multicolumn{12}{|l|}{ 厚壁菌门 Firmicutes } \\
\hline \multicolumn{2}{|c|}{ 类芽狍杆菌属 Paenibacillus } & & & 3 & - & & 1 & 1 & - & 1 & - \\
\hline JXR1 & Paenibacillus agarexedens (KC355292.1) & KР980588 & 100 & & & & & & & & \\
\hline JXR5 & Paenibacillus sp. (KJ000069.1) & КР980591 & 99 & & & & & & & & \\
\hline JXR30 & Paenibacillus vulneris (KM272755.1) & KP980604 & 100 & & & & & & & & \\
\hline 芽狍杆菌属 Bacillus & & & & 7 & 9 & 10 & 8 & 8 & 1 & 2 & 7 \\
\hline JXR2 & Bacillus cereus (KF831402.1) & KР980589 & 100 & & & & & & & & \\
\hline JXR3 & Bacillus sp. (JX566646.1) & KР980590 & 100 & & & & & & & & \\
\hline JXS6 & Bacillus subtilis (KP229430.1) & KP980578 & 100 & & & & & & & & \\
\hline JXS20 & Bacillus sp. (KM555037.1) & KP980585 & 100 & & & & & & & & \\
\hline JXS25 & Bacillus mojavensis (HQ123468.1) & КР980587 & 97 & & & & & & & & \\
\hline JXL24 & Bacillus sp. (KP119613.1) & KP980574 & 100 & & & & & & & & \\
\hline \multicolumn{2}{|c|}{ 赖氨酸芽孢杆菌属 Lysinibacillus } & & & 4 & - & 1 & 1 & - & 2 & 1 & 1 \\
\hline JXR13 & Lysinibacillus sphaericus (KM070813.1) & KР980597 & 100 & & & & & & & & \\
\hline JXL2 & Lysinibacillus fusiformis (JN867122.1) & КР980567 & 100 & & & & & & & & \\
\hline 总计 Total & & & & 34 & 28 & 32 & 23 & 18 & 16 & 12 & 25 \\
\hline
\end{tabular}

属, 芽孢杆菌科下有芽狍杆菌属(Bacillus)和赖氨酸 芽狍杆菌属(Lysinibacillus) 2属, 类芽孢杆菌科仅有 类芽孢杆菌属(Paenibacillus) 1属。芽狍杆菌属为厚 壁菌门中的优势属, 共分离到26株, 占分离总菌株 数的 $27.7 \%$ 。

从分离菌株数的比例来看, 芽孢杆菌属和微小 菌属为东乡野生稻内生细菌的优势菌属, 分别占分 离总株数的 $27.7 \%$ 和 $20.2 \%$, 枯草芽孢杆菌(Bacillus subtilis)和产左聚糖微杆菌(Microbacterium laevaniformans)为优势种, 分别占分离总菌株数的 $5.3 \%$ 和 $4.3 \%$ 。

\section{2 不同组织内生细菌群落组成及多样性}

\subsection{1 不同组织中内生细菌群落组成}

研究结果(表1, 图3)表明, 东乡野生稻根部共 分离到34株内生细菌(36.2\%), 包括12科14属; 茎部 共分离到28株内生细菌(29.8\%), 包括6科8属; 叶部 共分离到32株内生细菌(34.0\%), 包括7科9属。不动 杆菌属、类芽孢杆菌属、雷弗森菌属、红球菌属、 节杆菌属和分支杆菌属6属仅在根部分离获得; 寡 养单胞菌属和根瘤菌属2属仅在茎部分离获得; 泛
菌属、甲烷细菌属、微小菌属、短杆菌属、芽孢杆 菌属5属在根、茎和叶均有分布; 鞘氨醇单胞菌属、 土壤杆菌属、假单胞菌属、赖氨酸芽孢杆菌属4属 在根、茎和叶中至少两个不同组织内均有发现。比 较不同组织中内生细菌属的分布发现：根部优势属 (图3A) 为芽孢杆菌属, 有 7 株, 占根内菌株数的 $20.6 \%$; 茎部优势属(图3B)为芽孢杆菌属, 有 9 株, 占 茎部菌株数的32.1\%; 叶部优势属(图3C)为微小菌属 和芽狍杆菌属, 各有 10 株, 各占叶部菌株数的 $31.3 \%$ 。

\subsection{2 不同组织间内生细菌多样性}

从分离自东乡野生稻根部、茎部和叶部的内生 细菌多样性指数来看(表2), 根部内生细菌的Shannon-Wiener多样性指数、Simpson优势度指数和Pielou均匀度指数均最大, 分别为 $2.52 、 0.88$ 和 0.72 ; 茎 部内生细菌Shannon-Wiener多样性指数和Pielou均 匀度指数最小, 分别为 1.81 和 0.54 ; 叶部内生细菌 Simpson优势度指数最小, 为 0.74 , Shannon-Wiener 多样性指数和Pielou均匀度指数分别为 2.09 和 0.60 。 结果表明东乡野生稻不同组织内生细菌多样性为 

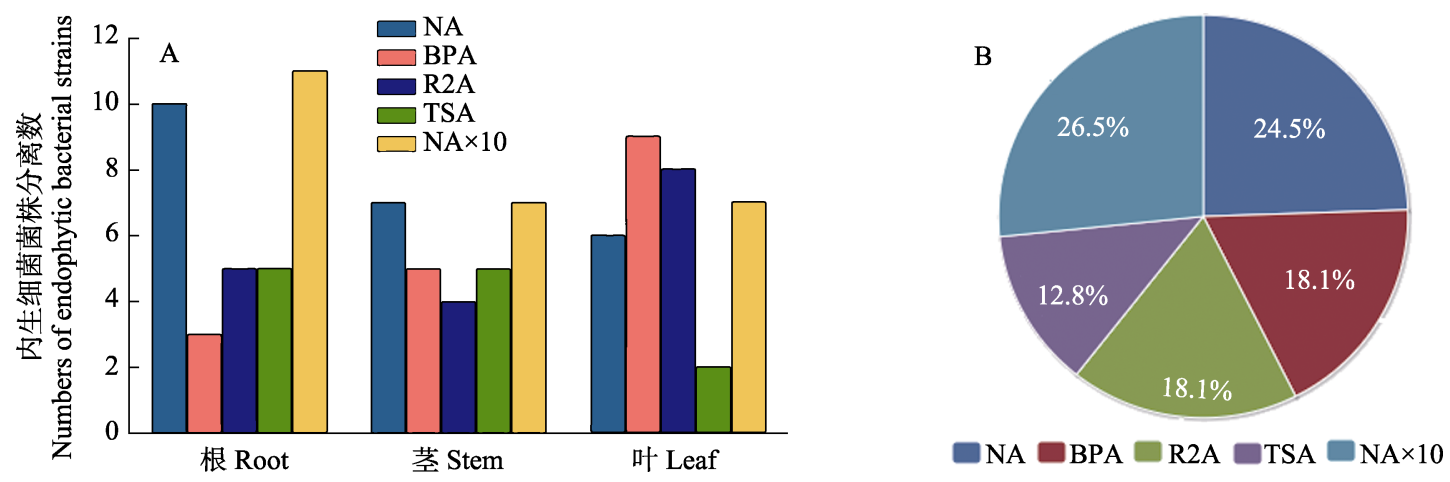

图1 东乡野生稻不同组织内生细菌在牛肉亳蛋白胨培养基(NA)、Baird-Parker agar (BPA)、任氏培养基(R2A)、胰酶大豆 琼脂培养基(TSA)和10倍稀释牛肉膏蛋白胨培养基(NA × 10)上的分离情况。(A)东乡野生稻不同组织在不同培养基中的分离 菌株数; (B)不同培养基分离菌株百分比。

Fig. 1 The endophytic bacteria isolated by nutrient agar, Baird-Parker agar, Reasoner's 2A agar Tryptone soy agar and 10-fold nutrient agar from each tissues of Dongxiang wild rice. (A) The amount of endophytic bacterial, derived from any tissues of Dongxiang wild rice, isolated from different mediums; (B) The percentage of the isolated strains from each medium.

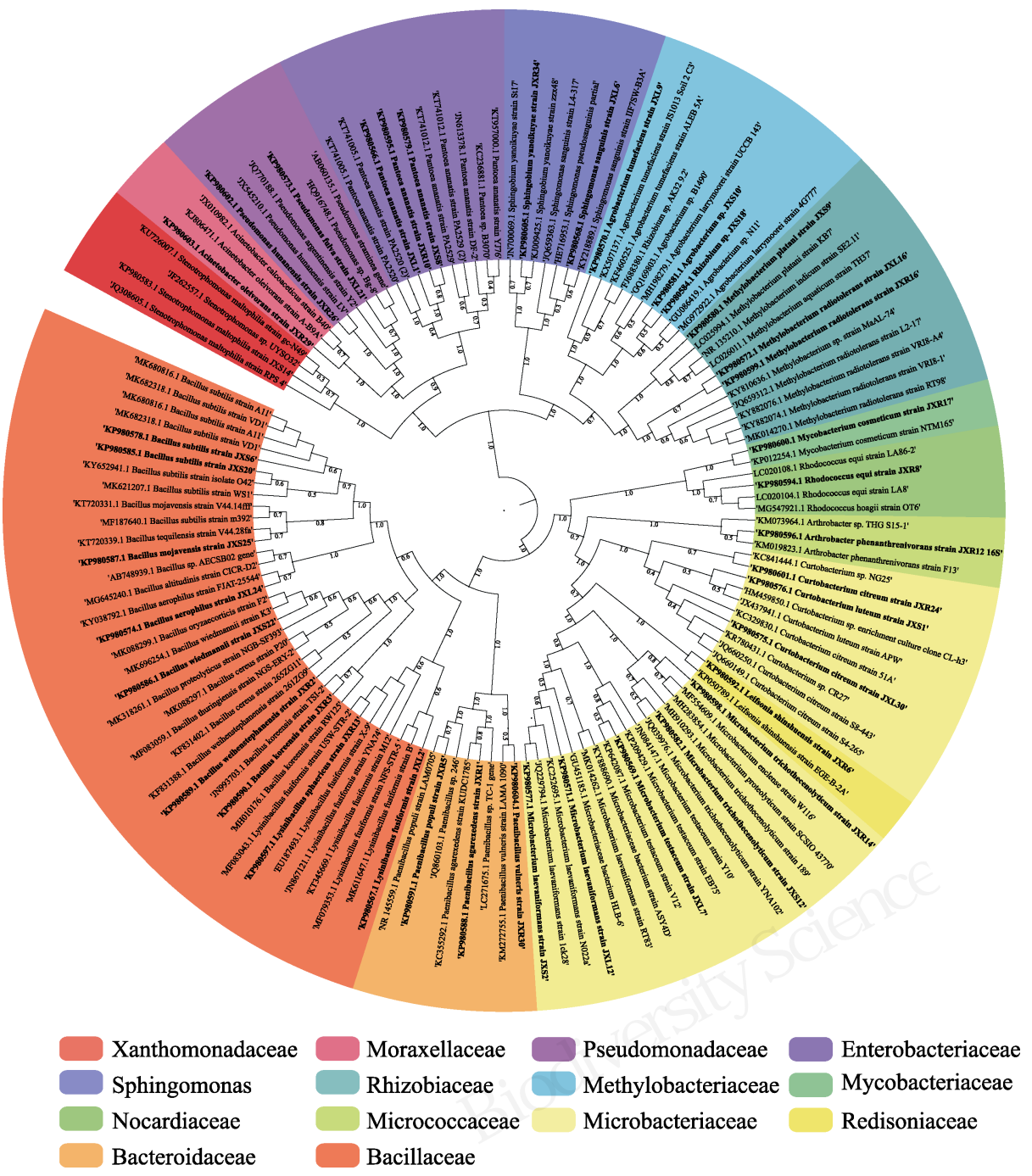

图2 东乡野生稻内生细菌16S rRNA基因序列系统进化树(分支中加粗菌株为东乡野生稻内生细菌, 非加粗菌株为近缘菌株) Fig. 2 Neighbor-joining tree based on 16S rRNA gene sequences showing the phylogenetic relationships among the strains and their closely related taxa. The thicker branches represent endophytic bacteria of Dongxiang wild rice and the others represent related strains. 


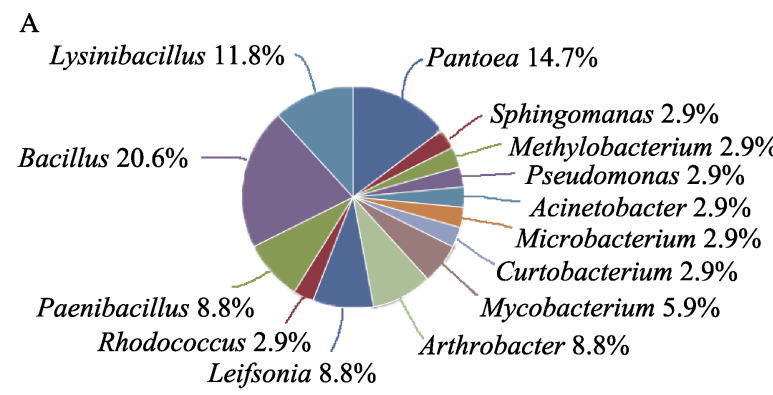

B
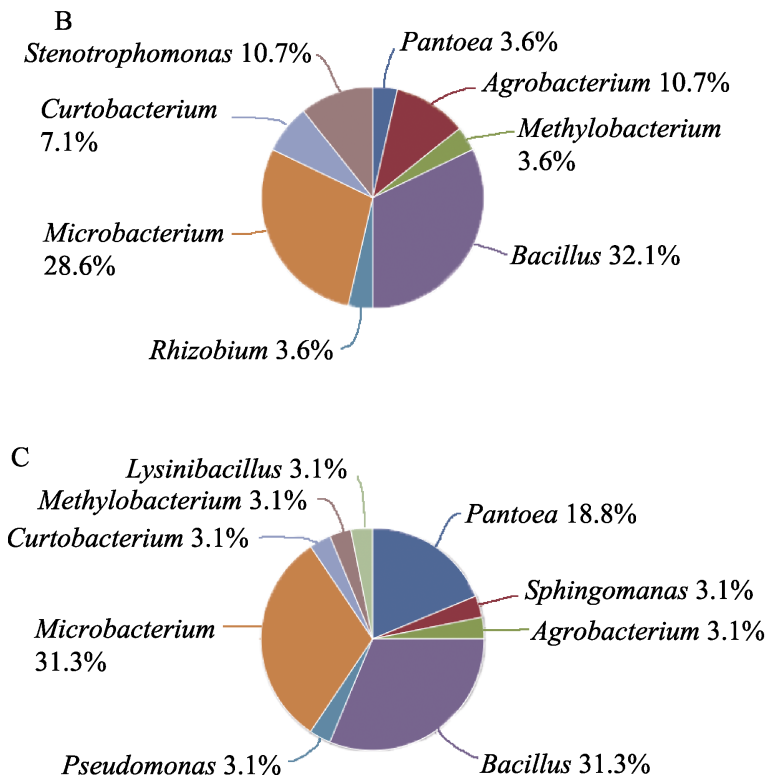

图3 东乡野生稻不同组织内生细菌属水平上的分布。(A) 根; (B)茎; (C)叶。

Fig. 3 Distribution of endophytic bacteria from different tissues of Dongxiang wild rice at the genus level. (A) Root; (B) Stem; (C) Leaf.

表2 东乡野生稻不同组织内生细菌的多样性指数(按属进 行计算)

Table 2 Diversity analysis of endophytic bacteria in different tissues of Dongxiang wild rice (according to genera)

\begin{tabular}{lllll}
\hline $\begin{array}{lll}\text { 组织名称 } \\
\text { Tissue }\end{array}$ & $\begin{array}{l}\text { 细菌属数 } \\
\text { Genus }\end{array}$ & $\begin{array}{l}\text { 多样性指数 } \\
\text { Shannon- } \\
\text { Wiener index }\end{array}$ & $\begin{array}{l}\text { 优势度指数 } \\
\text { Simpson } \\
\text { index }\end{array}$ & $\begin{array}{l}\text { 均匀度指数 } \\
\text { Pielou index }\end{array}$ \\
\hline 根 Root & 14 & 2.52 & 0.88 & 0.72 \\
茎 Stem & 8 & 1.81 & 0.80 & 0.54 \\
叶 Leaf & 9 & 2.09 & 0.74 & 0.60 \\
\hline
\end{tabular}

根部 > 叶部 > 茎部。

从东乡野生稻根部、茎部和叶部的内生细菌属 水平的Jaccard相似性指数来看, 叶部和根部、叶部 和茎部以及茎部和根部的相似性系数分别为 0.47 、 0.45 和 0.29 , 均值为 0.40 。整体来看, 东乡野生稻不 同组织可培养内生细菌相似性指数较低, 茎部和根
部的相似性系数明显低于叶部和根部以及叶部和 茎部, 表明根部内生细菌与叶部和茎部内生细菌有 明显不同。

\section{3 讨论}

\section{1 东乡野生稻内生细菌的群落组成}

水稻内生细菌对于宿主的生长发育(Zhou et al, 2016)、抗病抗逆性(Yang et al, 2008; Quan et al, 2018) 和抗虫害(Xia et al, 2009)等有着重要的作用, 因此, 从水稻中分离内生细菌并研究其群落组成和多样 性有助于阐明内生细菌在水稻生长过程中的作用 和功能。本研究采用 5 种分离培养基, 从东乡野生稻 根、茎和叶 3 种不同组织部位中共分离获得94株内 生细菌(图1), 隶属于3门14科17属(表1, 图2), 说明 东乡野生稻内生细菌资源丰富且分布广泛。

已有研究表明, 芽狍杆菌属、假单胞菌属和泛 菌属为水稻内生细菌的常见优势属(胡桂萍等, 2010; 黎起秦等, 2010), 本研究结果显示, 芽狍杆菌属和 微小菌属为东乡野生稻的优势内生菌属, 枯草芽孢 杆菌和产左聚糖微杆菌为优势内生菌种, 这和之前 关于栽培稻内生细菌的研究结果不完全一致 (Marcus et al, 2004; 孙硈, 2006; 李龚程等, 2015)。 内生细菌根瘤菌属、类芽孢杆菌属、肠杆菌属 (Enterobacter)、塞养单狍菌属、微小菌属、不动杆 菌属、鞘氨醇单胞菌属和土壤杆菌属等在栽培稻中 均有分离(Silo-Suh et al, 1994; 孙否, 2006; Mano \& Morisaki, 2008; 胡桂萍, $2010^{(1)}$ ), 但从东乡野生稻 分离到的一些内生细菌种属如分支杆菌属、红球菌 属、节杆菌属和短杆菌属则鲜有报道(图3)。东乡野 生稻(Zhang et al, 2016; 宋志平等, 2018)和已有报 道的水稻品种不同, 这可能是导致上述研究结果不 同的主要原因(赵娟等, 2015; 李楠楠等, 2017)。此 外, 生长的土壤环境、气候特点以及栽培措施(陈家 宽等, 1998)的不同也会导致其内环境与栽培稻有所 差异, 内环境的变化也会影响植株体内的营养成分, 进而对微生物群落有重要的影响(Nelson, 2004), 因 此东乡野生稻内生细菌的群落多样性不同于栽培 水稻, 可培养内生细菌种群组成也不同。

\section{2 不同组织内生细菌的分布和多样性分析}

由于植株各个营养组织所处的微环境不同, 植

(1) 胡桂萍 (2010) 水稻内生菌及其根系土壤微生物群落多样性的研究. 硕士学位论文, 福建农林大学, 福州. 
物内生细菌在组织中的分布存在明显差异, 部分内 生细菌有明显的偏好性(Dominika et al, 2018)。本文 研究了内生细菌在东乡野生稻不同组织内的分布 情况, 根部内生细菌菌株数量与多样性均高于茎部 和叶部(表1, 表2), 根部分离所得的菌株归属为 14 属, 明显多于茎部和叶部, 优势属为芽孢杆菌属(表 1, 图3C)。茎部和叶部的内生细菌多样性指数不高 (表2), 分离所得菌株分别归属8属和9属, 优势属为 芽狍杆菌属和假单胞菌属(图3A, B)。根部和茎部内 生细菌属水平的Jaccard相似性系数最低, 菌落组成 差异明显, 这可能是由于根部长有丰富的根毛, 增 加了根部与土壤的接触面积, 也增加了与根际土壤 微生物接触的几率, 因此根部较其他组织内生细菌 多样性更为丰富。已有报道表明, 茎部的内生细菌 丰富度相比叶部更高(黎起秦等, 2010; 王雪君等, 2015), 本研究中茎部和叶部的多样性指数比较接 近但相似性指数较低, 且寡养单胞菌属和根瘤菌属 仅在茎部分布(表1，图3B)。我们认为，空气中分布 的菌株能够通过水稻茎和叶的细胞壁进入水稻体 内, 一旦适应水稻内部的微环境, 将成为内生细菌 成员之一, 而茎部的内生细菌除了可以通过空气侵 染, 还可以通过茎部的维管束由植物根系从下到上 传递, 这可能是茎部和叶部所分离内生菌株种属差 异较大的原因。

\section{3 内生细菌与宿主抗逆相关性}

植物的许多内生细菌在提高宿主抗逆和促进 植物的生长发育方面具有明显作用(Faria et al, 2013; Tsavkelova et al, 2016), 如芽狍杆菌属、短小杆菌 属、假单胞菌属和泛菌属等植物内生细菌通过固 氮、溶磷、产IAA、分泌铁载体和产生抗菌活性物 质(Ryan et al, 2008; Santoyo et al, 2016)等方式帮助 宿主植物抵御生物和非生物胁迫。在本研究中, 从 东乡野生稻不同组织中分离所得的内生细菌优势 属为芽孢杆菌属和微小菌属, 这和之前报道的东乡 野生稻根际土壤微生物的优势属为芽孢杆菌属、泛 菌属和鞘氨醇单胞菌属(罗菲等, 2011)存在一些差 异, 但核心微生物芽狍杆菌属是一致的。

本研究中优势属芽孢杆菌属的代表菌株JXR2 的 16S rRNA基因序列与蜡样芽孢杆菌 (Bacillus cereus)相似性达 $100 \%$, 蜡样芽孢杆菌能够产生抗 菌活性物质(Silo-Suh et al, 1994)和防御酶, 提高植 株的免疫力(Marcus et al, 2004; 孙否, 2006; 李龚程
等，2015)，枯草芽孢杆菌、巨大芽孢杆菌(Bacillus megaterium)和短小芽狍杆菌(B. pumilus)对水稻稻 瘟病的防治和植物生长发育都有显著效果(沙月霞 等, 2018; Xie et al, 2019), 因此我们推测类似JXR2 的内生芽狍菌属菌株能够在一定程度上抑制某些 水稻病原菌的生长, 从而增强东乡野生稻的抗病 性。假单胞菌属的代表菌株JXL21与GenBank数据 库中的黄褐假单胞菌(Pseudomonas fulva) (登录号 AY741159.1)的16S rRNA的相似度为 $100 \%$, 该菌株 具有产铁载体的能力(Gerry et al, 2017), 因此推测 JXL21可能也为东乡野生稻在铁离子含量较少的环 境中提供铁载体。此外, 假单胞菌属和芽孢杆菌属 具有较强的溶磷能力(罗菲等, 2011), 短小杆菌属和 鞘氨醇单胞菌等能够帮助水稻在铁离子浓度较低 的环境中汲取铁离子(Loaces et al, 2011), 微小菌 属、泛菌属、土壤杆菌属和根瘤菌属等具有较强的 固氮能力(Mano \& Morisaki, 2008; 谭志远等, 2009), 它们在东乡野生稻可培养内生细菌中具有较高的丰 度，可能对东乡野生稻获取营养物质及增强抗病性 具有重要价值。

\section{参考文献}

Baldan E, Nigris S, Populin F, Zottini M, Squartini A, Baldan B (2014) Identification of culturable bacterial endophyte community isolated from tissues of Vitis vinifera "Glera". Plant Biosystems, 148, 508-516.

Brundrett MC, Tedersoo L (2018) Evolutionary history of mycorrhizal symbioses and global host plant diversity. New Phytologist, 220, 1108-1115.

Chen JK, Wang HY, He GQ (1998) A survey on the habitats of Oryza rufipogon and Isoetes sinensis in Jiangxi Province. Chinese Biodiversity, 6, 260-266. (in Chinese with English abstract) [陈家宽，王海洋，何国庆 (1998) 江西境内珍稀 植物普通野生稻和中华水非产地的考察. 生物多样性, 6, 260-266.]

Dai F, Huang YH, Peng WM, Li LM, Long ZE (2011) Studies on the microbial community in the rhizosphere soil of Dongxiang wild rice. Agricultural Science \& Technology, 12, 527-529.

Dominika T, Michal Z, Renata GK, Sonia S, Christel B, Katarzyna H (2018) Cadmium-induced changes in the production of siderophores by a plant growth promoting strain of Pseudomonas fulva. Journal of Basic Microbiology, 58, 623-632.

Dong XZ, Cai MY (2001) Manual for Systematic Identification of Common Bacteria. Science Press, Beijing. (in Chinese) [东秀珠, 蔡妙英 (2001) 常见细菌系统鉴定手册. 科学 出版社, 北京.] 
Faria DC, Dias ACF, Melo IS, de Carvalho Costa FE (2013) Endophytic bacteria isolated from orchid and their potential to promote plant growth. World Journal of Microbiology \& Biotechnology, 29, 217-221.

Gerry AJ, Rashid AY, Mahmoud WY (2017) Genome sequencing of Microbacterium sp. Yaish 1, a bacterial strain isolated from the rhizosphere of date palm trees affected by salinity. Microbiology Resource Announcements, 5, e01247-17.

Greenberg JH (1956) The measurement of linguistic diversity. Language, 32, 105-119.

Hu GP, You MS, Liu B, Zhu YJ, Zheng XF, Lin YZ (2010) Relationship between the stem endophytic and rhizosphere bacteria and the variety characteristics of Oryza sativa. Chinese Journal of Tropical Crops, 31, 1026-1030. (in Chinese with English abstract) [胡桂萍, 尤民生, 刘波, 朱 育菁, 郑雪芳, 林营志 (2010) 水稻茎部内生细菌及根际 细菌与水稻品种特性的相关性. 热带作物学报, 31, 1026-1030.]

James EK, Olivares FL (1998) Infection and colonization of sugar cane and other graminaceous plants by endophytic diazotrophs. Critical Reviews in Plant Sciences, 17, 77-119.

Li F, Guo SY, Zhao Y, Chen DZ, Chong K, Xu YY (2010) Overexpression of a homopeptide repeat-containing bHLH protein gene (OrbHLH001) from Dongxiang wild rice confers freezing and salt tolerance in transgenic Arabidopsis. Plant Cell Reports, 29, 977-986.

Li GC, Zhang SY, Xiao W, Long ZY, Zhang NM (2015) Research progress on endophytes in rice. Chinese Agricultural Science Bulletin, 31(12), 157-162. (in Chinese with English abstract) [李龚程, 张仕颖, 肖炜, 龙智勇, 张乃明 (2015) 水稻中内生菌研究进展. 中国农学通报, 31(12), 157-162.]

Li NN, Li N, Cao YH, Zhang X, Xiao M, Liu Y, Wang WP (2017) Diversity of endophytic bacterial communities in three parental seeds of hybrid rice (Oryza sativa L.) at maturity stage. Journal of Food Science and Technology, 35(4), 56-64. (in Chinese with English abstract) [李南南, 黎妮, 曹艳花, 张欣, 肖明, 刘洋, 王伟平 (2017) 3个杂 交水稻亲本成熟期种子内生细菌多样性研究. 食品科学 技术学报, 35(4), 56-64.]

Li QQ, Jiao C, Nong Q, Yuan GQ, Lin W, Huang YL (2010) Dynamic distribution of endophytic bacteria in rice from Guangxi and their antagonism to the pathogen of rice sheath blight. Chinese Journal of Biological Control, 26, 312-319. (in Chinese with English abstract) [黎起秦, 焦成, 农倩, 袁高庆, 林纬, 黄永禄 (2010) 广西水稻内生细菌的动态 分布及其对水稻纹枯病菌的拮抗作用. 中国生物防治, 26, 312-319.]

Liu XM, Yao Z, Shim JM, Lee KW, Kim HJ, Kim JH (2017) Properties of antimicrobial substances produced by Bacillus species isolated from rice straw. Microbiology and Biotechnology Letters, 45, 133-142.

Loaces I, Ferrando L, Scavino AF (2011) Dynamics, diversity and function of endophytic siderophore-producing bacteria in rice. Microbial Ecology, 61, 606-618.

Luo F, Wang Y, Zeng QG, Yan RM, Zhang ZB, Zhu D (2011) Diversity and plant growth promoting activities of the cultivable rhizo-bacteria of Dongxiang wild rice (Oryza rufipogon Griff.). Biodiversity Science, 19, 476-484. (in Chinese with English abstract) [罗菲, 汪涯, 曾庆桂, 颜日明, 张志 斌, 朱笃 (2011) 东乡野生稻根际可培养细菌多样性及 其植物促生活性分析. 生物多样性, 19, 476-484.]

Mano H, Morisaki H (2008) Endophytic bacteria in the rice plant. Microbes and Environments, 23, 109-117.

Marcus S, Ajay S, Owen PW (2004) Developments in the use of Bacillus species for industrial production. Canadian Journal of Microbiology, 50, 1-17.

Nelson EB (2004) Microbial dynamics and interactions in the spermosphere. Annual Review of Phytopathology, 42, 271-309.

Pavlova AS, Leontieva MR, Smirnova TA, Kolomeitseva GL, Netrusov AI, Tsavkelova EA (2017) Colonization strategy of the endophytic plant growth-promoting strains of Pseudomonas fluorescens and Klebsiella oxytoca on the seeds, seedlings and roots of the epiphytic orchid, Dendrobium nobile Lindl. Journal of Applied Microbiology, 123, 217-232.

Pielou EC (1966) The measurement of diversity in different types of biological collections. Journal of Theoretical Biology, 13, 131-144.

Quan RD, Wang J, Hui J, Bai HB, Lyu XL, Zhu YX, Zhang HW, Zhang ZJ, Li SH, Huang RF (2018) Improvement of salt tolerance using wild rice genes. Frontiers in Plant Science, 8, 2269-2280.

Rangjaroen C, Rerkasem B, Teaumroong N, Sungthong R, Lumyong S (2014) Comparative study of endophytic and endophytic diazotrophic bacterial communities across rice landraces grown in the highlands of northern Thailand. Archives of Microbiology, 196, 35-49.

Reinhold-Hurek B, Hurek T (2011) Living inside plants: Bacterial endophytes. Current Opinion in Plant Biology, 14, 435-443.

Ryan RP, Germaine K, Franks A, Ryan DJ, Dowling DN (2008) Bacterial endophytes: Recent developments and applications. FEMS Microbiology Letters, 278, 1-9.

Santoyo G, Moreno-Hagelsieb G, Orozco-Mosqueda MDC, Glick BR (2016) Plant growth-promoting bacterial endophytes. Microbiological Research, 183, 92-99.

Sha YX, Zeng QC, Wang X, Shen RQ, Liu H, Wang XG (2018) Screening and control efficiency evaluation of Bacillus against rice blast Magnaporthe oryzae. Chinese Journal of Biological Control, 34, 414-422. (in Chinese with English abstract) [沙月霞, 曾庆超, 王昕, 沈瑞清, 刘浩, 王喜刚 (2018) 防治稻瘟病芽胞杆菌的篮选及效果评价. 中国生物防治学报, 34, 414-422.]

Shahzad R, Waqas M, Khan AL, Al-Hosni K, Kang SM, Seo WC, Lee IJ (2017) Indoleacetic acid production and plant 
growth promoting potential of bacterial endophytes isolated from rice (Oryza sativa L.) seeds. Acta Biologica Hungarica, 68, 175-186.

Shannon CE (1948) A mathematical theory of communication. Bell System Technical Journal, 27, 379-423.

Shao SC, Burgess KS, Jennifer CJ, Liu Q, Fan XL, Hui H, Gao JY (2017) Using in situ symbiotic seed germination to restore over-collected medicinal orchids in Southwest China. Frontiers in Plant Science, 8, 888-898.

Shylla A, Shivaprakash MK, Shashidhar HE, Vishwakarma P, Sudradhar M (2016) Production of phytohormones by endophytic bacteria isolated from aerobic rice. Journal of Pure and Applied Microbiology, 10, 2127-2133.

Silo-Suh LA, Lethbridge BJ, Raffel SJ, Yin HH, Clardy J, Handelsman J (1994) Biological activities of two fungistatic antibiotics produced by Bacillus cereus UW85. Applied and Environmental Microbiology, 60, 2023-2030.

Song ZP, Chen JK, Zhao Y (2018) Rice domestication and the Yangtze River civilization. Biodiversity Science, 26, 346-356. (in Chinese with English abstract) [宋志平, 陈家 宽, 赵耀 (2018) 水稻驯化与长江文明. 生物多样性, 26, 346-356.]

Sun L (2006) Endophytic Bacteria and Root-Associated Bacteria with Rice by Culture-Independent and Culture-Dependent Approaches. PhD dissertation, Capital Normal University, Beijing. (in Chinese with English abstract) [孙否 (2006) 非培养方法和培养方法对水稻内生细菌和根结合 细菌的研究. 博士学位论文, 首都师范大学, 北京.]

Tan ZY, Peng GX, Xu PZ, Ai SY, Tang SH, Zhang GX, Zeng FY (2009) Diversity and high nitrogenase activity of endophytic diazotrophs isolated from Oryza rufipogon Griff. Chinese Science Bulletin, 54, 2839-2848. (in Chinese with English abstract) [谭志远, 彭桂香, 徐培智, 艾绍英, 唐拴虎, 张国霞, 曾风云 (2009) 普通野生稻(Oryza rufipogon)内 生固氮菌多样性及高固氮酶活性.科学通报, 54, 28392848.]

Tsavkelova EA, Cherdyntseva TA, Botina SG, Netrusov AI (2007) Bacteria associated with orchid roots and microbial production of auxin. Microbiological Research, 162, 69-76.

Tsavkelova EA, Egorova MA, Leontieva MR, Malakho SG, Kolomeitseva GL (2016) Dendrobium nobile Lindl. seed germination in co-cultures with diverse associated bacteria. Plant Growth Regulation, 80, 79-91.

Wang XJ, Jia RZ, Guo YL, Xu L, Zuo J, Kong H, Guo AP (2015) Diversity of culturable endobacterial communities in rice (Oryza sativa L.) stem at different growth stages.
Chinese Journal of Tropical Crops, 36, 1078-1085. (in Chinese with English abstract) [王雪君, 贾瑞宗, 郭运玲, 徐林, 左娇, 孔华, 郭安平 (2015) 水稻4个生长时期茎 部可培养内生菌多样性分析. 热带作物学报, 36, 1078-1085.]

Whittaker RH (1972) Evolution and measurement of species diversity. Taxon, 21, 213-251.

Xia H, Lu BR, Su J, Chen R, Rong J, Song ZP, Wang F (2009) Normal expression of insect-resistant transgene in progeny of common wild rice crossed with genetically modified rice: Its implication in ecological biosafety assessment. Theoretical and Applied Genetics, 119, 635-644.

Xie ZC, Chu YK, Zhang WJ, Lang DY, Zhang XH (2019) Bacillus pumilus alleviates drought stress and increases metabolite accumulation in Glycyrrhiza uralensis Fisch. Environmental and Experimental Botany, 158, 99-106.

Yang B, Chen Y, Li X, Ren CG, Dai CC (2013) Research progress on endophyte-promoted plant nitrogen assimilation and metabolism. Acta Ecologica Sinica, 33, 2656-2664. (in Chinese with English abstract) [杨波, 陈晏, 李霞, 任承钢, 戴传超 (2013) 植物内生菌促进宿主氮吸收与代谢研究 进展. 生态学报, 33, 2656-2664.]

Yang JH, Liu HX, Zhu GM, Pan YL, Xu LP, Guo JH (2008)Diversity analysis of antagonists from rice-associated bacteria and their application in biocontrol of rice diseases. Journal of Applied Microbiology, 104, 91-104.

Zhang FT, Xu T, Mao LY, Yan SY, Chen XW, Wu ZF, Chen R, Luo XD, Xie JK, Gao S (2016) Genome-wide analysis of Dongxiang wild rice (Oryza rufipogon Griff.) to investigate lost/acquired genes during rice domestication. BMC Plant Biology, 16, 103-114.

Zhao J, Liu T, Pan L, Jin BH, Zhao D, Chen C, Zhu YY, He $\mathrm{XH}$ (2015) Isolation and identification of root endophytic and rhizosphere bacteria of rice landraces in Yuanyang terrace, China. Chinese Journal of Applied Ecology, 26, 3737-3745. (in Chinese with English abstract) [赵娟, 刘涛, 潘磊, 靳百慧, 赵丹, 陈晨, 朱有勇, 何霞红 (2015) 元 阳梯田地方水稻品种根部内生菌及根际微生物的分离与 鉴定. 应用生态学报, 26, 3737-3745.]

Zhou Y, Yang P, Cui FL, Zhang FT, Luo XD, Xie JK (2016) Transcriptome analysis of salt stress responsiveness in the seedlings of Dongxiang wild rice (Oryza rufipogon Griff.). PLoS ONE, 11, e014624.

(责任编委：陈双林 责任编辑：时意专) 